\title{
Mer-Hagography: The Erasure, Return and Resonance of Splash's Older Mermaid
}

\section{ABSTRACT}

The 1984 feature film Splash initially included a scene featuring an embittered, older mermaid (referred to as the "Merhag" or "Sea-Hag" by the production team) that was deleted before the final version premiered. Since that excision, the older mermaid and the scene she appeared in have been recreated by fans and the mer/sea-hag has come to comprise a minor element in contemporary online culture. The term "Merhag," in particular, has also spread beyond the film, being taken up in fantasy fiction and being used-allusively and often pejoratively - to describe notional and actual female characters. Drawing on Mary Daly's 1978 exploration of supressed female experiences and perspectives, this essay first examines Splash and associated texts with regard to the general figure of the hag in western culture (and with regard to negative, ageist perceptions of the ageing female), before discussing the use of "Merhag" and "Sea-Hag" as allusive pejoratives and the manner in which their negative connotations have been countered.

Keywords: mermaids, merhags, sea-hags, hag-ography, Splash. 


\section{INTRODUCTION}

Throughout $20^{\text {th }}$ and early $21^{\text {st }}$ century western popular culture, and in audio-visual media in particular, the mermaid has been overwhelmingly represented with a youthful, (conventionally) attractive and lithesome human upper body and a sleek, scaled tail. In cinema, this figure was pioneered by Annette Kellerman in a series of marine-themed films in the 1910s and early 1920s and by actresses Ann Blyth and Glynis Johns in the late 1940s, in their respective light comedies Mr. Peabody and the Mermaid (Irving Pichel, 1948) and Miranda (Ken Annakin, 1948). Despite these precedents, perhaps no better example of the conventionally appealing mermaid exists than Madison, ${ }^{1}$ played by Daryl Hannah in Splash (Ron Howard, 1984). Advances in prosthetics, together with Hannah's prowess as an underwater swimmer, allowed her screen mermaid to combine allure with credibility as a denizen of the undersea realm. In western culture the mermaid has a rich duality. With her fishly lower half and lack of genitalia, which renders her unable to participate in conventional sexual congress, she is primarily represented as a problematic object of desire (at least, in terms of heterosexual interaction). But this factor also gives her an intriguing otherness. Skewing conventional gender binaries and delineations of human and non-human, she exists as a mythic figure capable of "swimming through" discourses and stimulating new reflections on subjectivity and positionality (Inkol). The first aspect has been negotiated in various ways in mainstream media, most obviously through the invention of the "transformative" mermaid (Hayward 91-109), who can switch between human and mer-form relatively easily ${ }^{2}$ (in Madison's case, simply by having her tail dried or her legs being splashed with water), allowing her to access the physical capabilities that a fully human form generates.

The main exception to representations of mermaids as wholly human in their upper part and wholly piscine in their lower, is the sub-type of the monstrous mermaid. The inhumanity of this variant is made apparent by her upper body being variously scaled and/or gilled and her face being rendered grotesque, usually by a fanged mouth. To complicate matters, many monstrous mermaids are also adaptive, in that they can switch between inhuman, marine predators and conventional, alluring mermaid form. Tamara, the mermaid in Pirates of the Caribbean: On Stranger Tides

1 It should be noted that I refer to Hannah's mermaid character as "Madison" (the name she chooses for herself when ashore in human form) in this essay since she reveals her actual name in the film via a set of high-pitched squeals that resists easy rendition in written form.

2 NB while the eponymous heroine of Andersen's short story "The Little Mermaid" (and Disney's subsequent filmic adaptation, 1989) undergoes transformation into human form, this is a painful and traumatic process that requires the intervention of an external agent. 
(Rob Marshall, 2011), played by Gemma Ward, or the central protagonist of the variously named Mamula/Killer Mermaid (Milan Todorovic, 2014), played by Zorana Obradovic, are notable examples of "switchers." In these cases, their glamorous, semi-human female physiques are presented as an alternate form used to mask their intractably inhuman nature. Almost entirely lacking in the history of $20^{\text {th }}$ and $21^{\text {st }}$ century audiovisual media are representations of mermaids whose upper, human forms are noticeably older and less (conventionally) attractive than the nubile stereotype. On those rare occasions when older mermaids appear, they are glamorously early-middle aged, such as the mermaid mothers played by Inga Tritt in the YouTube video series Mermaid Miracles (2014-15) or by Stephanie Chantel Durelli in the Disney Channel film The Thirteenth Year (Duwayne Dunham, 1999). Indeed, so complete is the absence of older, less conventionally attractive mermaids in mainstream cinema that the absence (or, more precisely, removal) of one from Splash before its release has attracted attention and various forms of fan engagement.

\section{SPLASH, MADISON AND THE MERHAG}

In the early 1980s there were two mermaid projects doing the rounds in Hollywood. One, developed by director Robert Towne, was slated to star Jessica Lange as a mermaid in a story about a disputed marine development (see Scriptshadow). While this project never made it to the screen, its rival, Splash, a light-hearted romcom project developed by producer Brian Grazer, was picked up by Disney as the debut film for their new, adult-oriented division, Touchstone Pictures. As Grazer and Fishman have detailed, the initial treatment was subject to multiple rewrites. One aspect that made it to the final shooting script (written in 1983 by Bruce Jay Friedman, Lowell Ganz and Babaloo Mandel) was a scene where Madison decides to go ashore and find her human love interest (played by Tom Hanks in the final film). In order to prepare herself, and to plan a journey from Cape Cod to New York, she seeks out maps from a sunken galleon. Entering the wreck, she is surprised to find an older mermaid who immediately engages with her, communicating in high pitched, dolphin-type squeals that were intended to be subtitled on-screen. The older mermaid draws on her own experience to warn Madison that if she assumes human form and goes ashore she will inevitably be rejected by her human lover when he discovers her alien identity. Realizing that Madison's mind is set, she instructs Madison that unless she wants to remain fixed in human form she will have to leave land before the full moon wanes. Suitably warned, Madison departs for New York and the human male she desires. 
The 1983 film script describes the senior mermaid as "a MERWOMAN, ${ }^{3}$ old and tired, with long flowing gray hair" (capitals in the original) and a "wrinkled, slightly mad-looking woman's face" ("J"). The scene was shot with stuntwoman and expert swimmer Marilyn Moe-Stader playing the merwoman and was included in an early, unreleased section of the film until it was deleted, never to re-appear in any extended "director's cut" nor to be featured as an additional sequence in deluxe DVD versions, etc.

Somewhat surprisingly, the deleted section featured prominently in a lengthy article by journalist Michael Mayo that appeared in the magazine Cinefantastique shortly before Splash's cinematic release. In terms of promotional logic, highlighting an element removed from a soon-to-bereleased product both complicates the launch of that product by suggesting a degree of uncertainty over its ideal form. In this regard, Mayo's coverage of the excised sequence merits discussion. His 1984 article provided an indepth account of the production of the film particularly concentrating on the nature of filming underwater, the design of Hannah's costume and of how the actress wore and performed in it. The older mermaid is featured twice, initially in a half page side panel (on page 97), showing photos of Moe-Stader being fitted with her costume, the costume itself and of the costume being worked on by a team member. Complementing the panel, the final page of the article devotes half of its word-length to further discussion of the older mermaid character and the sequence she appeared in. One of the most interesting aspects of the article concerns a significant shift in the design of the figure. Make-up and special effects supervisor Robert Short related that the initial concept for the figure originated from artist and costume designer May Routh, who stayed close to the script description quoted above by producing an illustration of a "gnarly, but elegant-looking old woman" who was a "sympathetic-looking character" as a guide for Short (Mayo 99). As previously noted, such an image of an older, elegant and sympathetic (albeit "slightly mad-looking") older mermaid would have been novel in western popular culture if it had made it to the screen. In the event, Routh's design didn't progress any further than her sketchpad, as Short decided to interpret the role of the older mermaid differently. Rather than follow Routh's model, he invented a far less attractive character who he came to refer to as the "Merhag" (Mayo 99). ${ }^{4}$

Short's designation is a significant one. I have not been able to detect any use of the term "Merhag" prior to 1984 and it is likely that at least some

3 "Merwoman" is a rarely used term and is presumably intended to distinguish her from the overwhelmingly youthful archetype of the mermaid.

4 I have been unable to ascertain whether Short originated the neologism himself or whether he adopted a term invented by another production team member. 
of the subsequent uses of the term have derived from reportage of Short's use of it (with regard to Splash) and its repetition in various contexts by aficionados of the film. But while the term "Merhag" may be novel, the latter part of the compound neologism is evocative for embodying a number of deep-set perceptions about older women in western patriarchal culture and in "man made" languages such as English (Spender). The term "hag" came into active English Language usage in the $16^{\text {th }}$ century and is now commonly used in a pejorative manner, being defined by the MerriamWebster Dictionary as referring to "an ugly, slatternly, or evil-looking old woman." There is also considerable colloquial usage of the term "hag" (along with "crone") to refer to post-menopausal women and a variety of associations of them being innately "deficient" as infertile, dried up, withered, etc. (see, for instance, Ferguson and Parry; or, for a popular media reflection on the topic, Cohen). The compound word "Merhag" used by Short combines these associations by substituting the term "maid" (traditionally a term used to describe a young, virgin/unmarried woman) as the second half of the compound.

Short's reconceptualization of the merwoman character was accepted by Howard and the production team created an "ugly and slatternly" figure in the following manner:

Robert Shiffer developed the makeup for the Merhag face and hair, and we did the rest-making her into a gnarly version of Daryl, with a shawl made out of fishnet and a moss vest for her upper body. We used a latex tail because the stiff way it bent and folded made her look ungainly and arthritic. All her makeup is grey, with just a little bit of orange. She's had a rough life and we wanted her to look it. (Short qtd. in Mayo 99)

As the panel copy on page 97 of Mayo's article details, the Merhag's tail was "wrinkled" and "adorned with sculpted barnacles, dead sea specimens and other assorted scraps" (ibid.). Other production stills reproduced online at the Splash blog site show her with gray, tangled hair.

While neither Short nor Howard (nor Glazer, who originally envisaged the project) have acknowledged any conscious influence or allusion, the Merhag character has substantial similarities to the sea-witch in Hans Christian Andersen's celebrated short story "The Little Mermaid." Andersen provides a scant description of the sea-witch, leaving it open for interpretation whether she has human, mer- or other form. ${ }^{5} \mathrm{He}$ principally characterizes her as unappealing for letting sea-snakes curl around her body

5 Disney films memorably visualized her as having a grotesque upper-body and face modelled on US drag performer Divine complemented by six long tentacles comprising her lower body (see Hayward 35-38 for discussion). 
and allowing a toad to eat directly from her mouth. Her unattractiveness is as marked in contrast to the Little Mermaid's beauty as the Merhag's is to Madison's. However, there is a significant difference with regard to the use of the character within the narrative. The Little Mermaid's encounter with the ugly sea-witch shifts the tone of Andersen's story, giving it a dark edge as the narrative moves to its sad conclusion (with the Little Mermaid being transformed into seafoam after she fails to secure the love of her cherished prince). By contrast, the Merhag sequence in Splash marks a temporary darkening of mood in a soft romcom that ends happily as its chief protagonists find love together in the ocean.

As Mayo relates, when Howard screened an early edit of the film he was "surprised to find that the underwater sequences weren't getting the expected reactions" (Mayo 99). Two (associated) reasons were given for the reaction. The first concerned the Merhag herself, towards whom viewers expressed an "antipathy," and the second concerned the scene with the Merhag, which they saw as "low-key and somewhat foreboding, and a bit at odds with the tone of the rest of the film" (ibid.). Faced with these negative responses, Howard decided to cut the galleon scene.

In an interview included in the Making of Splash featurette included on the $20^{\text {th }}$ Anniversary edition DVD released in 2004 (in which he referred to the character as the "Sea-Hag"6), Howard claimed that by removing the scene "there was a little more mystery about her [i.e. Madison] and we still would learn the rules as the film unfolded," creating a "comedic tension" that "made the story unfold in a more interesting way." The deletion of the Merhag scene was also significant in another regard. In a film produced, written, directed and costume designed by an all-male team in which Madison's physique and physical grace are lovingly followed by the camera and by the principal male characters, the Merhag scene stands out. Instead of seeing Madison through the eyes of male characters in point-of-view sequences, the film presents the Merhag as viewed by Madison (alone). This is, of course, a sleight-of-hand. The male gaze is still present as the metaperspective (and determines the broader cinematic "regime of looks") here but, nevertheless, the scene provides a representation of the two

6 It is unclear whether Howard was misremembering the term used in the production team some twenty years previously and defaulted to a similar term. If so, it is notable that the latter term has cultural pedigree, in that a character referred to as the Sea Hag was featured in the extended meta-text of the Popeye the Sailor franchise, first appearing in a Popeye cartoon strip in 1929 as an ugly, mannish (human-form) witch sailing the seas on a dark galleon and recurring in subsequent animated sequences. This usage, in turn, may reflect earlier folkloric sea hags such as the immense Cailleach Bheur of Gaelic mythology (see Harris). 
mer-characters interacting with each other, unseen by diegetic humans/ males. There is another distinct aspect. Whereas Madison's story is told through the film's tracking of her actions and physical transitions, the Merhag delivers a succinct account of her own history to Madison in mer-language. The subtitling is necessary as the audience does not have access to the linguistic codes they share. Speaking in her old, fluid language (which implicitly exists outside of the patriarchal discourses of human speech and its phonetic and aesthetic assemblages), she cautions Madison not to forsake her true form and take on human otherness in a bid to gain the love of a human.

Notwithstanding issues concerning her dialogue being written by male writers, her form created by male designers and her actress's actions directed by a male, the galleon scene is a particularly significant one. It can be understood as a moment when the Merhag acknowledges the impact that the pursuit of heterosexual love across the mer-/human divide has had on her. She urges the younger mermaid to stay true to her form and, thereby, stay true to her identity as an (aquatic) female:

Someday he'll find out about you. About what you are. And he'll hate you. And then it'll be too late to come back. And then you'll be like me. In no world. Just drifting. Growing old. In this ship. In the rotten remains of human misfortune. ("J.")

Despite this stark warning, the (unspoken) issue for Madison is that, in contemporary media-lore, at least, the merman is rarely alluded to and is often so absent from the undersea world that mermaids are largely presented (implicitly or defacto) as a female species - with all the unanswered questions such a situation brings. Hence, mermaids' frequent interest in and/or desire for congress with male humans within an aquatic order that has not [yet] been represented as complete in its singular gendering and/or been cast as a lesbian society. ${ }^{7}$ Recoiling from the compromise and rejection of her own foray into the world of humens, the Merhag seizes the opportunity to speak from her experience and of her identity. In so doing she evokes Mary Daly's reclamation of terms such as "hags" and "crones" for "gynocentric" (i.e. specifically female/feminist) purposes in her 1978 work Gyn/Ecology: The Metaethics of Radical Feminism. In this Daly asserts this identity/positionality can liberate the "hag" from her oppression within the ageist male patriarchal order:

7 Indeed, representations of lesbian mermaids are few and far between. The most notable are the mermaid in Gums (Robert J. Kaplan, 1976)—although her sexual desires are only shown in her interaction with a human female-and the mermaid cosplay participants in Mermaids and Unicorns (Madison Young, 2013). 
Hag is from an Old English word meaning harpy, witch. Webster's gives as the first and "archaic" meaning of hag: "a female demon: FURY, HARPY." It also formerly meant: "an evil or frightening spirit." (Lest this sound too negative, we should ask the relevant questions: "Evil" by whose definition? "Frightening" to whom?) A third archaic definition of hag is "nightmare." (The important question is: Whose nightmare?) Hag is also defined as "an ugly or evil-looking old woman.” But this, considering the source, may be considered a compliment. For the beauty of strong, creative women is "ugly" by misogynistic standards of "beauty." The look of female-identified women is "evil" to those who fear us. As for "old," ageism is a feature of phallic society. For women who have transvaluated this, a Crone is one who should be an example of strength, courage and wisdom. (15)

Returning to Short's description of his Merhag creation (qtd. in Mayo 99), it is also pertinent to note Daly's observation that those women who pursue radical life trajectories and/or means of understanding and expressing these "will become haggard":

But this term, like so many others, must be understood in its radical sense. Although haggard is commonly used to describe one who has a worn or emaciated appearance, this was not its original or primary meaning. Applied to a hawk, it means "untamed." So-called obsolete meanings given in Merriam-Webster include "intractable," "willful," "wanton," and "unchaste." The second meaning is "wild in appearance: as a) of the eyes: wild and staring b) of a person: WILD-EYED." Only after these meanings do we find the idea of "a worn or emaciated appearance." (16)

Daly's 1978 work is a rich and complex text that draws on her background in theology and her interest in myth and creative writing. In it she reflects on women's position in contemporary western culture and identifies means of breaking out of the deep structures of patriarchy and gaining autonomous expression. Drawing on the terminologies discussed above she calls for "Hag-ographies" or "Hagologies" that enable the uncovering of the herstories of hags. In these, as Campbell, emphasizes, hagographers "engaged in autobiographics do not merely write their lives; they create new contexts, new Space and Time, in which New Selves Weave Spells” (168).

As I have identified elsewhere (see Making a Splash), while mermaids are heavily imbued with and implicated within a Freudian discourse predicated on a phallocentric order, their agency and charisma are so marked that they can destabilize assumptions of female/feminine essences and roles. This aspect prompts a strong identification from both girls, who participate in the production and circulation of mermaid media texts and performances, and women who have similar aficionado sensibilities 
and outlets for cosplay and aquatic performance. Such engagements can generate what Daly termed a "gynergy" that can enable transformations of subjectivity and agency more generally.

While Mayo has asserted that Howard's decision to edit the galleon sequence sent "Short's Merhag into Davy Jones's locker," the Merhag eventually escaped its confines and appeared in other contexts. Since its release, Splash has acquired a considerable aficionado following that is evident in the (independent) Splash blog site that was established in 2010, gradually expanded through to 2014 and which has remained online through to the present. The site features text, including a number of interviews and production stills, and includes a page with photos of Moe-Stader from the excised film sequence under the heading "The Sea-Hag." When the original script for Splash became available to fans in 2009 (through unknown means), some aficionados created audiovisual sequences that attempted to recreate the lost scene. One such (anonymous) text, uploaded to YouTube under the title "Splash (1984)-The Sea hag (fan scene)," combined footage from the galleon sequence in the released film with a three second long snippet of Moe-Stadler in the role that was repeated, together with subtitled dialogue, in an approximation of the missing sequence. More inventively, artist Quihoma Isaac and editor Mario Escoto made a threeminute animated version of the sequence in the same year entitled SplashLa Bruja del Mar ("The Sea Witch"). While it was uploaded to YouTube under the modified title of Splash-The Sea Hag, its original designation suggests an association with Andersen's aforementioned character. In the animation, the older mermaid appears in the last minute of the sequence with gray hair, a motley green tail and wearing a fish net draped about her upper body (as in the original production stills featured in Mayo). Providing an original embellishment to the scene in the original script, Madison and the viewer first see the older mermaid as she catches a fish in her mouth and bites into it, releasing a spurt of red blood into the water (and suggesting her as resilient, vigorous and capable rather than weak and ineffective). The sequence then includes the interaction between Madison and the Merhag from the 1983 script (referred to above) as subtitles over a sound mix that includes dolphin noises standing in for mermaid voices.

Appropriating Daly's concepts to a fictional context, we can perceive the aficionados who recreated the missing Splash sequence to have effectively been working to return the Merhag's hag-ographical integrity erased by Splash's male production team. It is notable, in this regard, that Daly emphasizes erasure as a key tactic in patriarchal repression of women, referencing it sixty times in Gyn/Ecology and identifying it as one of the key aspects of male control and of the texts that support male hegemony and history (11). 


\section{THE HAG TERMS IN BROADER CIRCULATION}

Given that Howard does not appear to have used the term "Sea Hag" in public prior to the release of the 2004 DVD featurette, it is unlikely that any uses of the term "Sea Hag" in popular culture that occurred between 1984 and 2004 reference or are otherwise inspired by Splash's version of that persona. Yet, at the same time, the novel use of the term "Sea Hag" to refer to a mermaid following Splash's release, indicates—at least—a degree of synchrony in the popular cultural sphere. One such example concerns the adoption of the name for a heavy rock band formed in San Francisco in 1985. The band's debut album—entitled Sea Hags—was released in 1989 with a cover featuring a malevolent-looking mermaid (presumably, given the context, understood to be a "Sea Hag") whose appearance was pitched at something of a midpoint between Madison and Splash's Merhag. A number of fantasy fiction authors have also adopted the term. John Jackson's 2009 novel Aradithia: Rise of the Goblin King has a notably original twist, featuring merhags as loathsome, fork-tongued transformations of young human maidens who can be returned to their former state by kissing a male virgin. Further developments of the term and entity have also occurred within the bodies of inventive cultural practice often referred to as media-lore (a modern, mass-mediated version of traditional folklore that has become particularly prevalent on the Internet). In this context, Sea Hags have also been rendered as a more monstrous mermaids with fish-like heads who are "deformed and considered barren" and-reinstating the most pejorative uses of the term- "are jealous of those blessed with beauty and working sexual organs and will become violent if mocked" (Matria_mods).

Subsequent to Splash's deleted scene (and the alternative monikers for its mature mermaid character), the next appearance of a similarly named individual in mainstream media occurred in 2002, in season 5 episode 1 of the US TV series Charmed. The sea hag in the episode resembles the sea witch of Andersen's "Little Mermaid" in that she facilitates mermaids' transitions to human form in order to gain power from them. Unlike Andersen's story, however, she is not represented as loathsome, appearing in the episode as somewhat glamorous, long-haired, vaguely pre-Raphaelite, fully human figure. Indeed, her appearance-and the etymological duality of the term "hag"-is alluded to in the episode's dialogue, when one of the lead characters, Piper, asks another "when you said, uh, sea hag, did you mean like 'old woman hag' or 'evil magic hag'?" to which Mylie replies "Uh, she's kinda both." Despite the evil aspects of her role she is represented as markedly more conventionally attractive than her counterpart in Splash. Other positive uses of the name Sea Hag have been more playful, such as wall-plaques and mugs marketed online bearing a mermaid's image and the 
slogan "Sea-Hag-Mermaid without coffee," and the signs for Sea Hags Bar and Grill in St Petersburg Beach, Florida, and Sea Hags and Scallywags giftshop in Yarmouth, Nova Scotia, which feature traditionally attractive young mermaids on their sign. But despite these light-hearted uses of the terms, they have also become used pejoratively to describe middle-aged to older women in some online media.

While issues concerning the language of ageism—highlighted by writers such as Nuessel, and of sexism, addressed by writers such as Silveira and Spender, and aspects of both explored by Daly-were first advanced some forty years ago, there appears to have been little progress on these fronts in social media contexts. Looking up the terms "Merhag" and "Sea Hag" in the user-sourced, online Urban Dictionary (established in 1999) proves salutary. The Dictionary occupies an uneasy position between providing up-to-date documentation of a variety of vernacular terms and being a platform for wilfully offensive elaborations and inventions of terms and usages. Under "Merhag," for instance, the dictionary has the following:

a middle aged milf with droopy tits often seen in water, washing her aged vag. a typical day for merhag includes a dozen blowjobs for the nearest alpha male. other than giving blowjobs, merhags are fairly rare and hard to find.

[Example] Debbie is a such a merhag that she needs to DIAF. ${ }^{8}$ (Schmordon)

Under "Sea Hag," the Urban Dictionary offers two definitions provided by different (also male) authors that are similar in tone:

"Sea Hags" are found in most coastal communities in Southern California and in many other beach environments throughout the world. They usually were cursed from early age with having large breasts and developed "out of control" egos from over attention by horny boys and men. They tend to have bleached blond hair and favor green \& blue eye shadow. ... They usually dress $20+$ years younger than their age and from a distance might look attractive in a cheap "Barbie doll/hooker" sort of way, but up close, their shallow contempt emanates through their caked on makeup which easily betrays their age. On contact with a Sea Hag a feeling of mistrust and revulsion will come upon you due to the putrescence emanating from their lost souls.... All Sea Hags are trouble-makers and several of their favorite past-times are sleeping with married men, pitting men in fights against each other over them in bars and befriending people to later betray them for their own selfish ends [.]

[Example] Nina is such a "Sea Hag." (De La Rosa)

8 DIAF is an abbreviation for the term "die in a fire." 
And, by the tellingly named "Sea hag victim" in 2009:

A sea hag is a woman that didn't treat you right. Abruptly and loudly tell her to get out of your life by making only one surf-casting gesture that ends in a pointing finger and say "You didn't treat me right! Back to the sea with the rest of the hags you sea hag ... that's the way it is!" Also, don't feel bad about it or try to figure out why she didn't treat you right 'cause you'll go crazy. And, you can't get in trouble for calling someone a sea hag, but you can for other stuff.

[Example] Back to the sea with the rest of the hags you sea hag ... that's the way it is!

As will be apparent, these "definitions" express multiple loathings of the aging female, her changing physique and her sexuality. The second definition is particularly striking for its use of extreme terms such as "revulsion" and "putrescence," not to mention its spiritual-theological dimension, referring to their "lost souls" and quest for "TRUTH." As Mary Daly would no doubt would have interjected, "lost" to whom? "Revolting to whom? And whose "TRUTH"?

A number of women have engaged with hag terms differently, attempting to rehabilitate them as terms of endearment and respect in an example of what Sundén and Paasonen refer to as the tactical "appropriation of hateful terminology" by "cultural feminists." In Elizabeth Stuckey-French's 2002 novel Mermaids on the Moon, for instance, a group of older mermaid performers at the (fictional) Mermaid Springs attraction (modelled on Florida's Weeki Wachee Springs) call themselves "the Merhags." Similarly, illustrator Lauren Scott has produced a series of amiable and attractive images of relatively youthful mermaids identified as Merhags on her blog site Scotty's Sketches.

One of the most notable applications of the term "Merhag" to a specific individual involved Debra Beebe, a participant in the "reality" TV programme Survivor: Tocantins (2009). Beebe's nickname originated on social media and was used to variously describe, critique and defend her appearance and behaviour on the programme by various discussants. The Survivor formula involves a group of (usually fit) individuals being transported to an isolatedand usually semi-/tropical-location where they have to fend for themselves in shifting patterns of competition and collaboration with their fellow contestants. A series of tasks unfolds and contestants are progressively voted out until one person remains and wins the program's prize. Survivor has had a fairly wide viewing demographic since its introduction and has also been significant in retaining 18-49 year-old viewers at a time when that sector have been drifting away from broadcast television (Koblin). Viewers engage with the series in a number of ways, one of which involves participation in 
discussion fora where the relative merits and likeability of participants are debated, often in highly partisan manners. While demographic analyses of these fora are not available, the ID images used by posters, and vernacular terms and sub-cultural references used, suggest that participants are skewed to the lower range of the show's demographics. Beebe's nickname appears to have resulted from her being a 46-year old individual amidst a group of younger contestants and also concerns the manner she was introduced to her audience. Along with a brief sequence of her diving into a river in the initial opening montage of the show, her formal introduction was filmed while she sat waist-deep in shallow water, wearing a cleavage-revealing top with her blonde hair down (in a type of image more usually associated with mainstream and social media representations of younger women). While it is unclear when the appellation "Merhag" was first used, it was adopted in two Tapatalk chat group threads initiated in January 2009, when the show first went to air.

Adopting a redemptive use of the designation and a degree of reverence, a poster identifying as young female named Pinoyako established a thread entitled "Merhag's Graceful Shrine." There were over 73 postings on this thread including a variety of statements concerning how "hot" (i.e. sexually attractive) Beebe was as an older woman; enthusiastic characterizations of her as a contestant (some referring to her as "Debbiegoddess"); and postings of key sequences of her from the series. Another, shorter thread entitled "Debbie Beebe-Merhag-Love Club," also included references to her as "Merhagoddess" and featured a sharp retort from the list originator, char99bok, to a poster who referred to Beebe as a "wench." Notably, in these contexts, the "hag" component of the term was—at most—weakly pejorative as a characterization of age and seems to have been used with a degree of "cynical irony." In his discussion of the latter topic, Bennett explores the complexities of distinguishing between the representational/discursive aspect of (certain uses of) language and the passive irony that (supposedly) uses characterizations such as Merhag in perpetual parentheses, i.e. "Merhag" but-simultaneously_not Mer-hag (with all the cultural "baggage" of the latter). But, as Daly emphasizes, this "baggage" is so weighty that it is not easily dispensed with and is valuable, in that regard, in that it can be detournéd and can provide the basis for a more liberatory discourse.

\section{CONCLUSION_LEARNING FROM ERASURE}

The markedly different inflections of the Mer- and Sea-Hag terms in the social media contexts discussed in the above section illustrate the active and unsettled nature of the terms' uses. If the (male) production team's 
references to Splash's older mermaid, and subsequent uses of these in aficionado contexts can be taken to mark the origination of "Merhag" and the contemporary reinflection of "Sea-Hag" (from its use in Popeye), we can see a complex entangling of language and discourse over thirty-five decades. The erasure of the hag-mermaid created by the male production team on Splash can be seen, contextually, as a reflection of the hag's potential to destabilize dominant media stereotypes of female form and function. In this manner it could be analogized to a troubling "genie" that the producers tried to cram back into a bottle before that was cracked open by aficionados. Once liberated, the "-hag" forms entered online discourse and became used in a range of contexts, from the most regressive, ageist and misogynist (i.e. the Urban Dictionary definitions), through to more redemptive and affirmatory ones. In the middle ground of these is the usage that Bennett identifies as "sceptical," when words are invariably used to mean not quite what they suggest themselves to be. But such a situation is highly contextual. While-as in his case study of in-jokes concerning "Chavs" - there may be a wide sense of "knowingness" in the circuits in which such jokes occur; it is not so clear that there are such shared perspectival points in social media uses of the "-hag" terms discussed in this article. As the polarization of uses detailed above suggest, the stakes are (still) high in such deliberations over gender, age and stereotyping, pointing for the need for recurrent hag-ographies to engage with hegemonic media culture and with the allusive media-loric figures it produces.

It will come as no surprise to those acquainted with tabloid media that-as with all other ageing female film, tv and popular music stars-an ageing Daryl Hannah has been pilloried for showing the effects of time in the years that have passed since her appearance as an ingénue in Splash. The hyper-ageist and hyper-sexist discourse of such coverage has seen her predictably recast as a "hag." Commenting on changes on her facial appearance over a thirty-year period and her recent use of plastic surgery, an item in Radaronline in 2012 was headlined "Daryl Hannah Has Gone From Splash Siren To 'Scary Fish Lips,' Says Plastic Surgeon.” The article went on to contend that such interventionist procedures appeared contrary to Hannah's environmental activism (with groups such as Sea Shepherd and in opposition to the Keystone oil pipeline). Similarly, an item in the National Enquirer in 2015 was headlined "From Hot to Haggard!" and contended that "something's gone fishy with Daryl Hannah's face."

The situation experienced by ageing female public figures is fraught. Such women usually recognize that their looks have been an important

$9 \quad$ A British term describing young, brash and/or uneducated individuals usuallyalthough not exclusively_from low socio-economic backgrounds. 
aspect of their professional employability and marketability and, hence, their identity construction and personal charisma. As time affects them, they may seek cosmetic surgery to remain "in the game" but, at the same time, risk critique (and/or mockery) if external observers believe that such modifications have been either excessive or unsightly. The embrace of haggardness and of giving vent to one's own hag-ography are onerous options for individuals culturally and industrially conditioned to working in environments where ageism and sexism are so deeply rooted. In this manner, the deleted Merhag scene could be analogized as a cautionary tale for women interested in entering the fickle-and highly ageist-glamour machine of contemporary media. The scene's restoration and analysis thereby serves to continue critiques of modern media industries and attempts to identify alternative roles and pathways for women in society and on-screen.

Thanks to Claire Butkus and Marea Mitchell for their comments on an early draft of this article.

\section{Works CiTED}

“A Witch's Tail.” Charmed, created by James Conway, season 5, episode 1, Paramount Pictures, 2002.

Andersen, Hans Christian. "The Little Mermaid.” HCA.Gilead.org.il, 13 Dec. 2007, http://hca.gilead.org.il/li_merma.html, accessed 10 Feb. 2020.

Bennett, Joe. "The Critical Problem of Cynical Irony Meaning What You Say and Ideologies of Class and Gender." Social Semiotics, vol. 26, no. 3, 2016, pp. 250-64. https://doi.org/10.1080/10350330.2015.113 4819

Campbell, Debra. "Be-ing Is Be/Leaving." Feminist Interpretations of Mary Daly, edited by Sarah Lucia Hoagland and Marilyn Faye, The Pennsylvania State UP, 2000, pp. 164-93.

Cohen, Claire. "Hag, Harridan, Crone: 16 Words We Only Use to Describe Older Women.” The Telegraph, 20 Mar. 2018, https://www.telegraph. co.uk/women/life/hag-harridan-crone-16-words-use-describe-olderwomen/, accessed 20 Feb. 2020.

Daly, Mary. Gyn/Ecology: The Metaethics of Radical Feminism. Beacon, 1978.

De La Rosa, Ian. “Sea Hag.” Urban Dictionary, 13 June 2013, https://www. urbandictionary.com/define.php? term $=\mathrm{Sea} \% 20 \mathrm{Hag}$, accessed $22 \mathrm{Feb}$. 2020. 
Emery, Debbie. "Daryl Hannah Has Gone From Splash Siren To 'Scary Fish Lips,' Says Plastic Surgeon.” Radar, 2 Oct. 2012, https://radaronline. com/exclusives/2012/10/daryl-hannah-plastic-surgery-photos-troutpout/, accessed 10 Feb. 2020.

Fantasy Games Central. “Debra 'Debbie' 'Merhag' Beebe.” Tapatalk, 2009, https://www.tapatalk.com/groups/fgc/, accessed 2 May 2020.

Ferguson, Susan J., and Carla Parry. "Identity, the Body, and the Menopause." Frontiers: A Journal of Women Studies, vol. 19, no. 1, 1998, pp. 20-41. https://doi.org/10.2307/3347130

Friedman, Bruce Jay, Lowell Ganz, and Babaloo Mandel. Splash (script). 1983.

Grazer, Brian, and Charles Fishman. A Curious Mind: The Secret to a Bigger Life. Simon and Schuster, 2015.

Gums. Directed by Robert J. Kaplan, performances by Theodore Gottlieb and Terri Hall, Cum Laude Films, 1976.

"Hag." Merriam-Webster, https://www.merriam-webster.com/dictionary/ hag, accessed 11 Apr. 2020.

Harris, Jason Marc. "Perilous Shores: The Unfathomable Supernaturalism of Water in $19^{\text {th }}$-Century Scottish Folklore." Mythlore: A Journal of J. R. R. Tolkien, C. S. Lewis, Charles Williams, and Mythopoeic Literature, vol. 28, no. 1, 2009, pp. 5-25.

Hayward, Philip. Making a Splash: Mermaids (and Mermen) in 20th and 21 $1^{\text {st }}$ Century Audiovisual Media. John Libbey/Indiana UP, 2017. https:// doi.org/10.2307/j.ctt200605w

Inkol, Cecelia. "Melusine Machine: The Metal Mermaids of Jung, Deleuze and Guattari." Shima, vol. 12, no. 2, 2018, pp. 52-65. https://doi. org/10.21463/shima.12.2.07

"J." "Splash From Script to Screen: Script to Move comparison: Part 1." Splash Blogspot, 24 Apr. 2013, http://themoviesplash.blogspot.com/2013/04/ script-to-movie-comparison-part-i.html, accessed 18 Feb. 2020.

Jackson, John G. Araditbia: Rise of the Goblin King. iUniverse, 2009.

Koblin, John. "Survivor Defies Gravity to Hang On as CBS Ratings Stalwart." The New York Times, 30 Sept. 2015, https://www.nytimes. $\mathrm{com} / 2015 / 10 / 01 /$ business/media/survivor-defies-gravity-to-hangon-as-cbs-ratings-stalwart.html, accessed 28 Apr. 2020.

Mamula (a.k.a.KillerMermaid). Directed by Milan Todorovic, performances by Kristina Klebe and Franco Nero, Viktorija Film, 2014.

Matria_mods. "Beach Creatures [Merhag]." Matria_mods Livejournal, 7 Dec. 2008, https://matria-mods.livejournal.com/1703.html, accessed 10 Feb. 2020.

Mayo, Michael. "Splash." Cinefantastique, vol. 14, no. 3, 1984, pp. 92-99. https://doi.org/10.1017/S0002021400007854 
Mermaid Miracles. Directed by Brett Mazurek, YouTube.com, uploaded by Mermaid Miracles Reuploaded, 2014-15, https://www.youtube.com/ channel/UCJcsj6A1Zgruz-7YYoIAPFA/featured, accessed 1 May 2020.

Mermaids and Unicorns. Directed by Madison Young, performances by Ela Darling and Madison Young, 2014.

Miranda. Directed by Ken Annakin, performances by Glynis Johns and Googie Withers, Sydney Box Productions, 1948.

Mr. Peabody and the Mermaid. Directed by Irving Pichel, performances by Ann Blyth and William Powell, Inter-John Productions, 1948.

National Enquirer. "Daryl Hannah: From Hot to Haggard!" National Enquirer, 1 Oct. 2015, https://webcache.googleusercontent.com/ search?q= cache:ZEbhpxE-IJEJ:https://www.nationalenquirer.com/ celebrity/daryl-hannah-hot-haggard $/+\& \mathrm{~cd}=2 \& \mathrm{hl}=\mathrm{pl} \& \mathrm{ct}=\mathrm{clnk} \& \mathrm{~g}$ l=pl, accessed 27 Feb. 2020.

Nuessel, Frank H. Jr. "The Language of Ageism.” The Gerontologist, vol. 22, no. 3, 1982, pp. 273-76. https://doi.org/10.1093/geront/ 22.3.273

Pirates of the Caribbean: On Stranger Tides. Directed by Rob Marshall, performances by Penélope Cruz and Johnny Depp, Walt Disney Pictures, 2011.

Schmordon, Schmichael. "Merhag." Urban Dictionary, 15 Mar. 2009, https://www.urbandictionary.com/define.php?term=merhag, accessed 22 Feb. 2020.

Scott, Lauren. “Scotty's Sketches.” Scotty's Sketches, http://scottysketches. blogspot.com/, accessed 22 Feb. 2020.

Scriptshadow. "Screenplay Review-The Mermaid." Scriptshadow, 20 Feb. 2013, http://scriptshadow.net/screenplay-review-the-mermaid/, accessed 18 Feb. 2020.

Sea Hags. Sea Hags. Chrysalis, 1989.

Sea hag victim. "Sea Hag." Urban Dictionary, 26 Feb. 2009, https://www. urbandictionary.com/define.php? term $=$ Sea $\% 20 \mathrm{Hag}$, accessed $11 \mathrm{Feb}$. 2020.

Silveira, Jeanette. "Generic Masculine Words and Thinking.” The Voices and Words of Women and Men, edited by Ed Cheris Kramarae, Pergamon, 1980, pp. 165-78. https://doi.org/10.1016/S0148-0685(80)92113-2

Spender, Dale. Man Made Language. Pandora, 1980.

Splash. Directed by Ron Howard, performances by Tom Hanks and Daryl Hannah, Touchstone Pictures, 1984.

Splash Blogspot. "The Sea-Hag." Splash Blogspot, 19 Feb. 2010, http:// themoviesplash.blogspot.com/2010/02/sea-hag.html, accessed 18 Feb. 2020. 
Splash_La Bruja del Mar. Directed by Quihoma Isaac and Mario Escoto. YouTube.com, uploaded by SplashTheSeaHag, 5 Oct. 2009, https:// www.youtube.com/watch?v=8JMkRej7zLk, accessed 2 Apr. 2020.

"Splash (1984)-The Sea hag (fan scene)." YouTube.com, uploaded by Mermaidsworld, 19 Jan. 2009, https://www.youtube.com/ watch? $\mathrm{v}=\mathrm{dRf}$ ASgdChQ, accessed 11 Mar. 2020.

Stuckey-French, Elizabeth. Mermaids on the Moon. Anchor, 2002.

Sundén, Jenny, and Susanna Paasonen. "Shameless Hags and Tolerance Whores: Feminist Resistance and the Affective Circuits of Online Hate." Feminist Media Studies, vol. 18, no. 4, 2020, pp. 634-65. https:// doi.org/10.1080/14680777.2018.1447427

Survivor: Tocantins. Season 18, CBS, 2009.

The Little Mermaid. Directed by Ron Clements and John Musker, Walt Disney Pictures, 1989.

The Thirteenth Year. Directed by Duwayne Dunham, performances by Justin Jon Ross and Chez Starbuck, Dream City Films, 1999.

\section{Philip Hayward is Adjunct Professor at University of} Technology Sydney, Australia, and is editor of the journal Shima. He has written widely on a number of media and cultural studies topics. His books include Making a Splash: Mermaids (and Mermen) in 20th and $21^{\text {st }}$ Century Audiovisual Media (JLP/Indiana UP, 2017). https://orcid.org/0000-0002-0018-0174 philip.hayward@uts.edu.au 